\title{
Correction to: Growth and elongation of axons through mechanical tension mediated by fluorescent-magnetic bifunctional $\mathrm{Fe}_{3} \mathrm{O}_{4} \cdot$ Rhodamine 6G@PDA superparticles
}

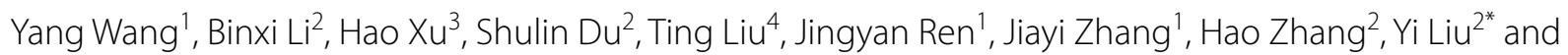
Laijin Lu ${ }^{1^{*}}$ (i)

\section{Correction to: J Nanobiotechnol (2020) 18:64}

https://doi.org/10.1186/s12951-020-00621-6

The authors regret errors in Fig. 2a, b, d and $g$ in the originally published article [1]. In Fig. 2a, b and d, the TEM/ HRTEM images and the magnetic curve of FMSPs were not the correct ones. These mistakes came from the confusion of the images and the curves. In Fig. 2g, the authors wish to use the different PL excitation and emission spectra of FMSPs to their another article. The authors apologize for these mistakes and are now providing the correct TEM/HRTEM images and magnetic curve, and the new PL excitation/emission spectra of FMSPs in Fig. 2. All the data herein are accurate and reproducible. These corrections do not affect the conclusion of this article.

(c) The Author(s) 2021. This article is licensed under a Creative Commons Attribution 4.0 International License, which permits use, sharing, adaptation, distribution and reproduction in any medium or format, as long as you give appropriate credit to the original author(s) and the source, provide a link to the Creative Commons licence, and indicate if changes were made. The images or other third party material in this article are included in the article's Creative Commons licence, unless indicated otherwise in a credit line to the material. If material is not included in the article's Creative Commons licence and your intended use is not permitted by statutory regulation or exceeds the permitted use, you will need to obtain permission directly from the copyright holder. To view a copy of this licence, visit http://creativeco mmons.org/licenses/by/4.0/. The Creative Commons Public Domain Dedication waiver (http://creativecommons.org/publicdomain/ zero/1.0/) applies to the data made available in this article, unless otherwise stated in a credit line to the data. 

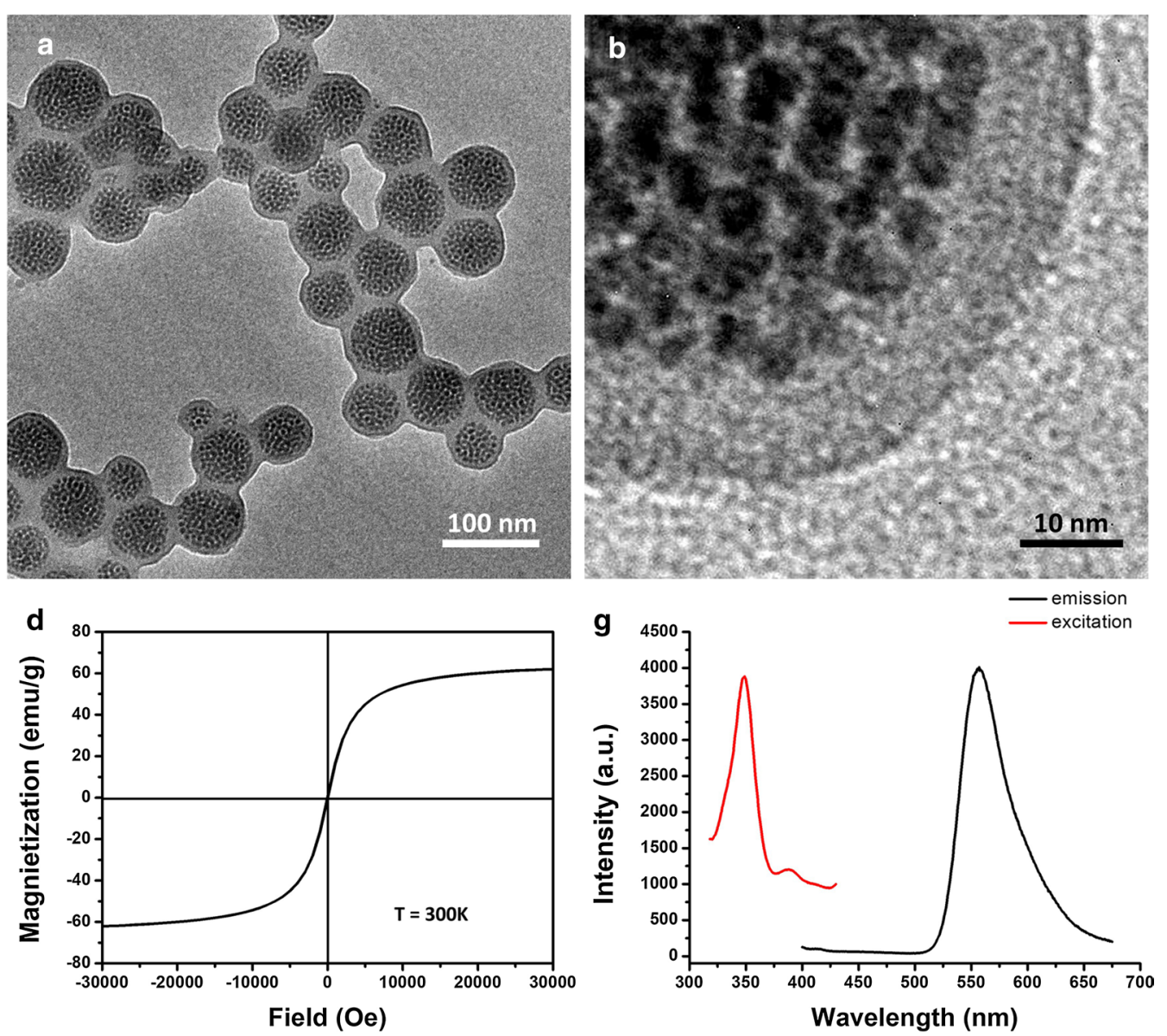

Fig. 2 TEM (a) and HRTEM (b) images of FMSPs. d Magnetic curve of FMSPS. $\mathbf{g}$ PL emission and excitation spectra of FMSPS

\section{Author details}

'Department of Hand Surgery, The First Hospital of Jilin University, Changchun 130021, People's Republic of China. ${ }^{2}$ State Key Laboratory of Supramolecular Structure and Materials, College of Chemistry, Jilin University, Changchun 130012, People's Republic of China. ${ }^{3}$ Institute of Translational Medicine, The First Hospital of Jilin University, Changchun 130021, People's Republic of China. ${ }^{4}$ Departments of Geriatrics, The First Hospital of Jilin University, Changchun 130021, People's Republic of China.

Published online: 17 May 2021

\section{Reference}

1. Wang Y, Li B, Xu H, Du S, Liu T, Ren J, Zhang J, Zhang H, Liu Y, Lu L. Growth and elongation of axons through mechanical tension mediated by fluorescent-magnetic bifunctional $\mathrm{Fe}_{3} \mathrm{O}_{4}$ Rhodamine 6G@ PDA superparticles. J Nanobiotechnol. 2020;18:64. https://doi.org/10.1186/ s12951-020-00621-6.

\section{Publisher's Note}

Springer Nature remains neutral with regard to jurisdictional claims in published maps and institutional affiliations. 